\title{
Pneumothorax during laparoscopic totally extraperitoneal inguinal hernia repair -A case report-
}

\author{
Hye Young Kim ${ }^{1}$, Tae-Yop Kim², Kyu Chang Lee ${ }^{1}$, Myeong Jong Lee ${ }^{1}$, Seong-Hyop Kim², \\ Jong Min Bahn ${ }^{1}$, Eun Kyung Choi ${ }^{1}$, and Ji Yeon $\mathrm{Kim}^{3}$ \\ Department of Anesthesiology and Pain Medicine, ${ }^{1}$ Chungju Hospital, Konkuk University School of Medicine, Chungju, ${ }^{2}$ Seoul \\ Hospital, Konkuk University School of Medicine, Seoul, ${ }^{3}$ Inje University College of Medicine, Ilsan Paik Hospital, Goyang, Korea
}

We experienced an extremely rare complication during performance of laparoscopic totally extraperitoneal (TEP) inguinal hernia repair for a 57-year-old healthy man. About 50 minutes after $\mathrm{CO}_{2}$ insufflation, the patient developed tachycardia, hypoxemia, hypercapnia and an increased airway pressure. Right pneumothorax with subcutaneous emphysema was recognized on the emergency chest X-ray and this was successfully treated by chest tube insertion. Anesthesiologists should be aware of the possible occurrence of pneumothorax during laparoscopic TEP hernia repair. (Korean J Anesthesiol 2010; 58: 490-494)

Key Words: Hernia repair, Laparoscopy, Pneumothorax, Subcutaneous emphysema.

The frequency of endoscopic surgeries based on laparoscopy or thoracoscopy has increased in recent years and the introduction of new surgical techniques has caused an increased occurrence of pneumothorax. During laparoscopic surgery, the use of carbon dioxide to secure the surgical space and visual field can cause such conditions as subcutaneous emphysema, pneumothorax, pneumomediastinum, pneumopericardium and gas embolism [1]. There are many reported cases in which pneumothorax occurred during laparoscopic surgery. Yet pneumothorax is rare and unexpected when performing laparoscopic surgery for the management of inguinal hernia.

We experienced a case of pneumothorax that occurred during laparoscopic totally extraperitoneal inguinal hernia repair with hemodynamic instability. Pneumothorax has not been previously reported during laparoscopic TEP hernia repair in the country. Herein we report our case with a review of the literature.

\section{Case Report}

A 56-year-old man with a weight of $65 \mathrm{~kg}$ and a height of 172 $\mathrm{cm}$ visited with a chief complaint of a 2-month-history of a mass in the left inguinal area. The patient was diagnosed with a left inguinal hernia and then he was hospitalized for laparoscopic TEP hernia repair. The preoperative laboratory findings were all within the normal ranges. Normal findings were seen on the

Received: February 3, 2010. Revised: 1st, February 3, 2010; 2nd, March 26, 2010. Accepted: May 1, 2010.

Corresponding author: Tae-Yop Kim, M.D., Department of Anesthesiology and Pain Medicine, Seoul Hospital, Konkuk University School of Medicine, Hwang-dong, Kwangjin-gu, Seoul 143-729, Korea. Tel: 82-2-2030-5445, Fax: 82-2-2030-5449, E-mail: pondkim@unitel.co.kr (c) This is an open-access article distributed under the terms of the Creative Commons Attribution Non-Commercial License (http:// creativecommons.org/licenses/by-nc/3.0/), which permits unrestricted non-commercial use, distribution, and reproduction in any medium, provided the original work is properly cited. 
preoperative chest radiography, the EKG and the pulmonary function tests (Fig. 1).

The patient was premedicated with midazolam $2 \mathrm{mg}$ and glycopyrrolate $0.2 \mathrm{mg}$ intramuscularly 30 minutes before anesthesia. Following arrival at the operation room, the blood pressure was $150 / 90 \mathrm{mmHg}$, the heart rate was 85 times/min and the peripheral $\mathrm{O}_{2}$ saturation was $98 \%$. For the induction of anesthesia, $100 \%$ oxygen was administered by using a mask. Thiopental sodium $300 \mathrm{mg}$ and rocuronium $40 \mathrm{mg}$ were given intravenously, and this was followed by tracheal intubation. There were no problems during endotracheal intubation. Following confirmation that there were no problems with ventilation in both lungs, a tube was fixed in the area that was $23 \mathrm{~cm}$ away from the incisor.

The anesthesia was maintained with $\mathrm{O}_{2} 2.0 \mathrm{~L} / \mathrm{min}$, air $2.0 \mathrm{~L} /$ min, desflurane $4-6$ vol\% and remifentanil $0.3-0.5 \mu \mathrm{g} / \mathrm{min} / \mathrm{kg}$. Following the induction of anesthesia, mechanical ventilation was initiated at a tidal volume of $8 \mathrm{ml} / \mathrm{kg}$ and a respiratory rate of 12 breaths/min, which produced a peak airway pressure of 17-18 mmHg. At the start of surgery, the end-tidal $\mathrm{CO}_{2}$ was 32 $\mathrm{mmHg}$, the peripheral $\mathrm{O}_{2}$ saturation was $99-100 \%$, the blood pressure was $110 / 70 \mathrm{mmHg}$ and the heart rate was 85 times/ $\min$.

For the surgical procedure, with the use of a preperitoneal dissection balloon, a sufficient amount of space was secured between the posterior area of the transversus abdominus and the anterior area of the posterior rectus sheath and peritoneum. To secure the surgical vision in this extraperitoneal space, $\mathrm{CO}_{2}$ was then infused at an insufflation pressure of $12 \mathrm{mmHg}$. After $\mathrm{CO}_{2}$ insufflation, the peak inspiratory pressure and end-tidal

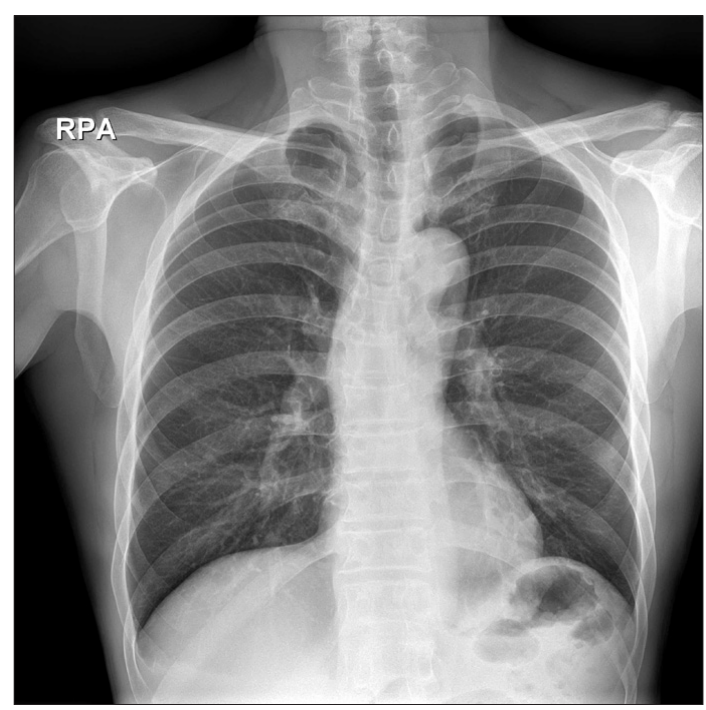

Fig. 1. The preoperative chest PA x-ray shows no abnormal findings in the lung.
$\mathrm{CO}_{2}$ were $17-18 \mathrm{mmHg}$ and $32-35 \mathrm{mmHg}$, respectively.

The anesthesia was well maintained without any specific problems. About 50 minutes after insufflation, the peripheral $\mathrm{O}_{2}$ saturation decreased from $100 \%$ to $96 \%$. The peak inspiratory airway pressure was $25-28 \mathrm{cmH}_{2} \mathrm{O}$ and the end-tidal $\mathrm{CO}_{2}$ was increased to $45-50 \mathrm{mmHg}$. The blood pressure was $80 / 48$ $\mathrm{mmHg}$ and the heart rate was 102 times/min. After ephedrine $8 \mathrm{mg}$ was administered, the blood pressure and heart rate increased to $110 / 55 \mathrm{mmHg}$ and 110 times/min, respectively. At this time, the arterial blood gas analysis showed a $\mathrm{pH}$ of 7.34, a $\mathrm{PaCO}_{2}$ of $58 \mathrm{mmHg}$, a $\mathrm{PaO}_{2}$ of $75 \mathrm{mmHg}$ and a $\mathrm{SaO}_{2}$ of $95 \%$. The fraction of inspired oxygen was increased to 1.0 . Manual ventilation was performed at this time. When the breath sounds were auscultated, the left respiratory sounds were normal, but the right respiratory sounds were markedly decreased. Under the suspicion that the endotracheal tube had migrated due to pneumoperitoneum or postural change, the tube was pulled out by $2 \mathrm{~cm}$. Auscultation was done after manual ventilation was performed several times. Yet the respiratory sounds were not improved in the right lung. There were almost no mucus materials during the aspiration with using an aspiration catheter. At the same time, the presence of subcutaneous emphysema was confirmed in the bilateral submental regions, the shoulder and the upper thoracic area. It was confirmed by surgeons that the trocar placement was not correct. But under the suspicion of pneumothorax in the right lung, a prompt resolution of the pneumoperitoneum was requested prior to further aggravating the condition of the patient. The $\mathrm{O}_{2}$ saturation did not further decrease from $96 \%$. The surgical procedure was completed 15 minutes after the

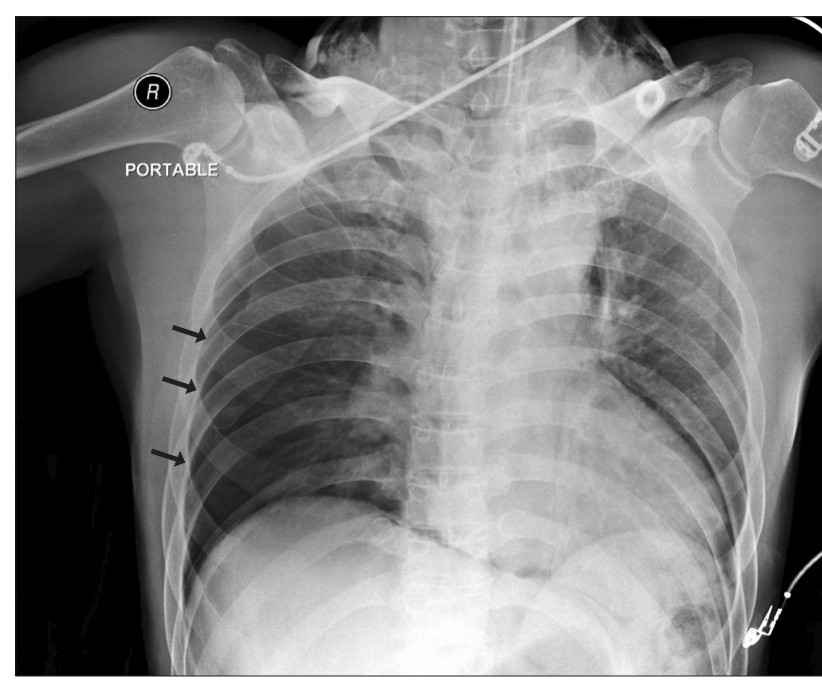

Fig. 2. The intraoperative chest AP x-ray shows pneumothorax (arrows) in the right lung with a mediastinal shift and subcutaneous emphysema. 


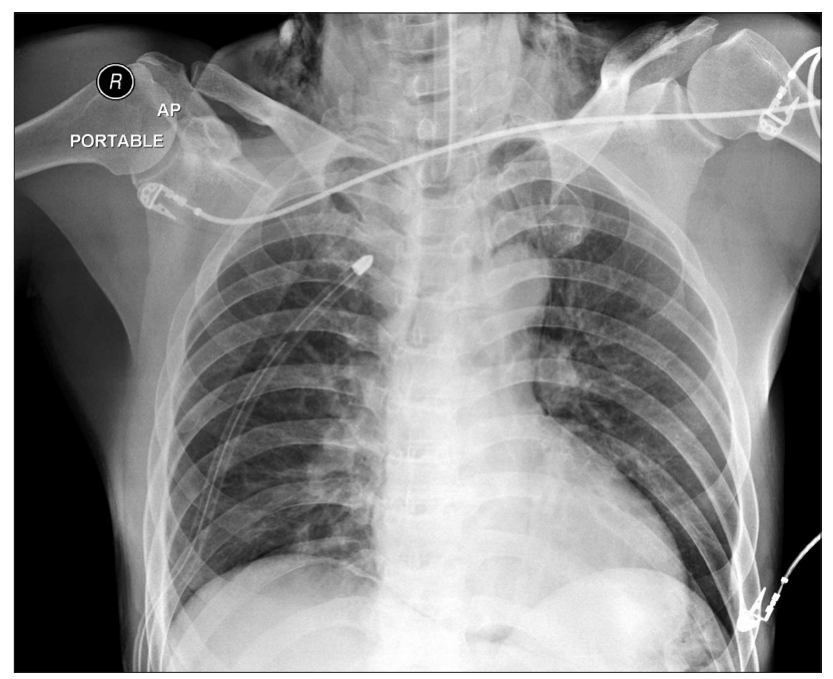

Fig. 3. The immediate post-operative chest AP x-ray shows a chest tube and no residual pneumothorax.

request to halt the pneumoperitoneum. With the resolution of the pneumoperitoneum, the peak airway pressure decreased to $21 \mathrm{cmH}_{2} \mathrm{O}$ and the end-tidal $\mathrm{CO}_{2}$ decreased to $37 \mathrm{mmHg}$. In addition, the $\mathrm{O}_{2}$ saturation improved from $96 \%$ to $98 \%$. The subcutaneous emphysema gradually decreased. A chest AP $\mathrm{X}$-ray was performed and this confirmed the occurrence of pneumothorax in the right lung (Fig. 2). Right thoracostomy was performed after consultation with the cardiothoracic surgeons. Following this, the respiratory sounds of the right lung were improved. The arterial blood gas analysis showed a $\mathrm{pH}$ of 7.34 , a $\mathrm{PaCO}_{2}$ of $44 \mathrm{mmHg}$, a $\mathrm{PaO}_{2}$ of $389 \mathrm{mmHg}$ and $\mathrm{a} \mathrm{SaO}_{2}$ of $99 \%$.

The patient returned to spontaneous respiration and he recovered consciousness. This was followed by removing the endotracheal tube. Except for the pain at the site of surgery, the patient did not complain of respiratory distress. The patient was then transferred to a recovery room. Using an oxygen mask, oxygen $5 \mathrm{~L} / \mathrm{min}$ was administered to the patient. The peripheral $\mathrm{O}_{2}$ saturation was persistently maintained over $99 \%$. Following the surgery, the disappearance of pneumothorax was confirmed on the chest X-ray that was performed again in a recovery room (Fig. 3). Thereafter, the patient was transferred to a ward. A chest $\mathrm{X}$-ray on the third post-operative day showed no abnormal findings, and the chest tube was removed. He was discharged on the 6th post-operative day without any complications.

\section{Discussion}

There is a trend that laparoscopic TEP inguinal hernia repair is now being performed as an alternative to traditional open repair or laparoscopic transabominal preperitoneal hernia repair. In particular, laparoscopic TEP hernia repair is a method that is favored for patients with recurrent or bilateral hernias [2]. The advantages of laparoscopic TEP inguinal hernia repair include a low recurrence rate and a reduced risk of intraabdominal infection or contamination, and damage to the intra-abdominal organs and adhesion, as compared with laparoscopic transabdominal preperitoneal hernia repair or an open procedure. It also causes less postoperative pain and it enables patients to promptly return to their daily lives [2-4].

There has been extensive discussion on the complications associated with the management of anesthesia during laparoscopic surgery [1]. Pneumothorax is one of the serious complications, although it rarely occurs in association with laparoscopic surgery. Yet in cases of laparoscopic TEP hernia repair, surgical procedures such as the insufflation of $\mathrm{CO}_{2}$ or the insertion of laparoscopic ports themselves are restricted to the extraperitoneal space. Accordingly, such complications as pneumothorax are not usually expected. However, its prevalence is likely to increase as the procedure continues to gain popularity. A few cases in the anesthesia literature describes that laparoscopic extraperitoneal hernia repair having been complicated by pneumothorax without hemodynamic instability and/or subcutaneous emphysema [5-8]. In our case, the patient developed intraoperatively pneumothorax with hemodynamic instability.

In cases of pneumothorax occurring during general anesthesia, such non-surgically related complications as barotrauma, damage to the bronchus during endotracheal intubation, rupture of congenital bulla or blebs, and side effects due to the insertion of a central venous catheter should also be considered. For the current case, endotracheal intubation was smoothly done for the induction of anesthesia. A central venous catheter was not inserted and an excessive extent of positive pressure ventilation was not performed. Accordingly, the complications of this case were assumed to have occurred in association with the surgical procedure. Based on the findings that the hemodynamic and respiratory parameters improved when the insufflation of $\mathrm{CO}_{2}$ gas was discontinued, the occurrence of pneumothorax due to a non-surgical cause could be ruled out.

For the current case, one of 2 possibilities or both were probably responsible for the occurrence of pneumothorax. The first was that $\mathrm{CO}_{2}$ entered the retroperitoneal space and then it entered the pleural space and mediastinum along the tissue plane $[6,9,10]$. This might be consistent with the pathway for which the subcutaneous emphysema occurred in the neck and upper chest area in the current case. Chien et al. [11] reported on three patients who developed subcutaneous emphysema in the neck and laryngopharyngeal areas. A hypothesis for the occurrence of subcutaneous emphysema is that $\mathrm{CO}_{2}$ enters the retroperitoneal space through a myopectineal dissection and then it reaches the neck. Accordingly, it has been reported 
that setting the insufflation pressure of $\mathrm{CO}_{2}$ below $10 \mathrm{mmHg}$ and keeping the insufflation time below 2 hours are helpful for preventing pneumothorax $[3,5]$. Shim et al. [10] reported that pneumothorax was occurred during retroperitoneal laparoscopic nephrectomy because insufflations pressures were over $15 \mathrm{mmHg}$. In the current case, the insufflation pressure was $12 \mathrm{mmHg}$ and this corresponded to a slightly higher level than the recommendation. But the insufflation time was approximately 70 minutes and this was not a long time. The second possibility is the incidental penetration of the peritoneum [7]. At the time of such a penetration, $\mathrm{CO}_{2}$ migrates due to congenital diaphragmatic defects such as a pleuroperitoneal canal or through the areas adjacent to the aorta or esophagus. In these cases, injury can also occur to the urinary bladder or bowels during the surgery, and there is also a possibility for postoperative adhesion Yet in the current case, the surgeons confirmed a lack of damage to the peritoneum during the surgery.

In cases in which pneumothorax occurs during general anesthesia, such symptoms as respiratory distress or chest pain cannot be detected. The differential diagnosis should also be made to exclude other causes for the decreased oxygen saturation, which may delay the diagnosis of pneumothorax. The treatment can vary depending on the causes and severity of the pneumothorax. Accordingly, identifying the causes is essential for cases in which pneumothorax occurs during general anesthesia. As for the signs indicating a pneumothorax, hypotension occurs due to the decreased venous return and cardiac output. In association with this, according to Hurewitz et al. [12], although hypotension occurs in cases of severe tension pneumothorax, the cardiac output is maintained in most cases and this may maintain the blood pressure. According to Barton [13], hypotension represents a substantial extent of the pneumothorax in cases of tension pneumothorax. Barton noted that early detection is essential prior to the occurrence of hypotension. In the current case, based on the findings that hypotension and tachycardia transiently occurred and mediastinal shift was detected on the chest X-ray that was performed following the discontinuation of $\mathrm{CO}_{2}$ insufflation, the possibility of the intraoperative occurrence of tension pneumothorax could not be ruled out.

The $\mathrm{CO}_{2}$ insufflation should be reduced or halted in cases in which pneumothorax is suspected or confirmed during laparoscopic TEP herniorrhaphy. The nitrous oxide should then be discontinued and the hyperventilation should be performed. In addition, the managements for hemodynamic stability should be maintained. Tube thoracostomy is not a mandatory procedure unless patients are hemodynamically unstable or their respiratory function is impaired because $\mathrm{CO}_{2}$ is promptly diffused from the body [6]. In most cases, the
$\mathrm{CO}_{2}$ is spontaneously lost within $30-60$ minutes following the release of the gas [14]. According to Joris et al. [15], maintaining the endotracheal intubation and elevating the positive endexpiratory pressure rather than a tube thoracostomy would be helpful for treating a pneumothorax that occurs during laparoscopic fundoplication. Yet in the current case, due to the occurrence of mediastinal shift on the chest X-ray, the hypotension and the tachycardia, a tube thoracostomy was performed for the safe management of the patient, following consultation with the cardiothoracic surgeons. As shown in the current case, when considering the possibility of airway obstruction due to pharyngeal emphysema, performing laryngoscopy prior to extubation would be helpful for cases in which subcutaneous emphysema occurs in the areas adjacent to the neck and face [11].

Pneumothorax is a rare, unexpected complication during laparoscopic TEP hernia repair, but there is a high possibility that the condition of a patient with pneumothorax can be aggravated and this may lead to death. To prevent this condition, clinicians should be interested in the pressure and time of the intraoperative insufflation of $\mathrm{CO}_{2}$. Anesthesiologists should closely monitor the alterations of the respiratory system such as the end-tidal $\mathrm{CO}_{2}$ and the peak airway pressure and also the hemodynamic indicators to detect any signs suggesting complications related to laparoscopic surgery. They should then perform the appropriate management as promptly as possible.

\section{References}

1. Gerges FJ, Kanazi GE, Jabbour-Khoury SI. Anesthesia for laparoscopy: a review. J Clin Anesth 2006; 18: 67-78.

2. Ramshaw BJ, Tucker JG, Conner T, Mason EM, Duncan TD, Lucas GW. A comparison of the approaches to laparoscopic herniorrhaphy. Surg Endosc 1996; 10: 29-32.

3. Kald A, Anderberg B, Smedh K, Karlsson M. Transperitoneal or totally extraperitoneal approach in laparoscopic hernia repair: results of 491 consecutive herniorrhaphies. Surg Laparosc Endosc 1997; 7: 86-9.

4. Chung RS, Rowland DY. Meta-analyses of randomized controlled trials of laparoscopic vs conventional inguinal hernia repairs. Surg Endosc 1999; 13: 689-94.

5. Ferzli GS, Kiel T, Hurwitz JB, Davidson P, Piperno B, Fiorillo MA, et al. Pneumothorax as a complication of laparoscopic inguinal hernia repair. Surg Endosc 1997; 11: 152-3.

6. Harkin CP, Sommerhaug EW, Mayer KL. An unexpected complication during laparoscopic herniorrhaphy. Anesth Analg 1999; 89: 1576-8.

7. Browne J, Murphy D, Shorten G. Pneumomediastinum, pneumothorax and subcutaneous emphysema complicating MIS herniorrhaphy. Can J Anaesth 2000; 47: 69-72.

8. Bartelmaos T, Blanc R, De Claviere G, Benhamou D. Delayed pneumomediastinum and pneumothorax complicating laparoscopic extraperitoneal inguinal hernia repair. J Clin Anesth 
2005; 17: 209-12.

9. Cunningham AJ. Laparoscopic surgery-anesthetic implications. Surg Endosc 1994; 8: 1272-84.

10. Shim HS, Park SH, Ryu DH, Kim IK, Shin MK. Pneumothorax during retroperitoneal laparoscopic nephrectomy. Korean J Anesthesiol 2005; 48: 324-7.

11. Chien GL, Soifer BE. Pharyngeal emphysema with airway obstruction as a consequence of laparoscopic inguinal herniorrhaphy. Anesth Analg 1995; 80: 201-3.

12. Hurewitz AN, Sidhu U, Bergofsky EH, Leff B, Averbuch I, Grimson
$\mathrm{R}$, et al. Cardiovascular and respiratory consequences of tension pneumothorax. Bull Eur Physiopathol Respir 1986; 22: 545-9.

13. Barton ED. Tension pneumothorax. Curr Opin Pulm Med 1999; 5: 269-74.

14. Togal T, Gulhas N, Cicek M, Teksan H, Ersoy O. Carbon dioxide pneumothorax during laparoscopic surgery. Surg Endosc 2002; 16: 1242.

15. Joris JL, Chiche JD, Lamy ML. Pneumothorax during laparoscopic fundoplication: diagnosis and treatment with positive endexpiratory pressure. Anesth Analg 1995; 81: 993-1000. 